\title{
FORMACIÓN CIUDADANA Y ENSEÑANZA DE LAS CIENCIAS SOCIALES
}

\author{
Carlos Mauricio Canjura Linares \\ Ministro de Educación de El Salvador
}

Antes que nada permítanme decirles que me siento muy satisfecho de tener un auditorio tan amplio para un tema que creo es fundamental para el país, y que vamos rompiendo esa tradición en la que temas importantes del país se discuten con muy pocas gentes.

Quiero, primeramente, plantear la gran preocupación que tenemos en el Ministerio de Educación (MINED), tal y como lo expresó el coordinador del Centro Nacional de Investigaciones en Ciencias Sociales y $\mathrm{Hu}-$ manidades (CENICSH), Lic. Carlos Enrique Rodríguez, el tema central del sistema educativo es desarrollar en nuestros jóvenes capacidades productivas y capacidades ciudadanas. Esto debe ser nuestro referente. Si nosotros no somos capaces de construir generaciones que tengan altas capacidades productivas y buenas capacidades ciudadanas no hay ninguna duda que por más que dominen los contenidos como sistema educativo, entonces, hemos fracasado.

Y la realidad de nuestro sistema educativo creo que a todos nosotros nos preocupa porque cuando evaluamos lo que nuestros jóvenes, tras 11 años de escuela, pueden desde el punto de vista productivo para insertarse 
en la sociedad, nos encontramos realmente con mucha debilidad, y creo que la misma situación que vivimos en estos momentos como sociedad refleja que tampoco desde el punto de vista de la construcción de una ciudadanía responsable estamos haciendo una labor aceptable. Es momento entonces de debatir este tipo de cosas y por esa razón me alegra que haya una buena presencia este día, pues nos dará la oportunidad de que vayamos posicionando esta problemática ante la sociedad salvadoreña.

Nosotros hemos asumido una línea de trabajo en la recuperación de nuestro sistema educativo que está enfatizando el trabajo con los maestros. Nos hemos ocupado, casi desde que iniciamos la gestión 2009-2014 del tema de maestros, y lo hemos hecho tratando de fortalecer las capacidades disciplinares de nuestra planta docente porque creo que es grosero decir que la planta docente nacional, desde el punto de vista disciplinar, es débil.

Por ello, debemos hacer el esfuerzo para que nuestros maestros alcancen excelentes niveles de formación y lo hemos venido haciendo porque estamos convencidos de que esa corriente, según la cual de lo que se trata es de fortalecer solo metodologías, es insuficiente; y sobre todo cuando no se parte de un dominio razonable de una disciplina todo lo metodológico queda en el vacío. Creemos que es importante aclararnos que la mejor didáctica de cualquier disciplina se construye cuando se tienen excelentes dominios de la disciplina.

Es muy atrevido creer que se puede lograr un buen planteamiento didáctico sin un dominio bueno de los contenidos que se administran. Ese es el primer esfuerzo que estamos haciendo y que arrancamos ya directamente con los maestros el 24 de enero de 2015, y consideramos que estamos desarrollando un trabajo que está logrando el desarrollo de la capacidad docente a nivel nacional y sobre todo ese desarrollo que hemos intentado hacer equilibrado regionalmente.

Nos hemos preocupado que en este proceso de formación estén representados todos los departamentos del país en las diferentes disciplinas y obviamente como hay departamentos que tienen enormes moras, entonces 
en este proceso cuando monitoreamos cómo va la ubicación geográfica de toda la planta de especialistas que estamos construyendo, esas debilidades se muestran siempre, sin embargo, estamos logrando tener una buena cantidad de especialistas en una buena cantidad de departamentos.

Esos déficits son los que tiene nuestra sociedad en cuanto a los equilibrios que debieran tener los desarrollos de los departamentos: el desarrollo de departamentos como Morazán, Cabañas, San Vicente, comparándolo con el de San Salvador de la Libertad, Santa Ana o San Miguel, son muy diferentes y se reflejan a la hora de construir esta planta de especialistas. En este sentido de construir la planta de especialistas vamos trabajando razonablemente, pero creo que debemos ir más allá y debemos orientar todo el esfuerzo en la dirección de construir capacidades productivas y ciudadanas.

En ese sentido tenemos que ir imaginando cómo transformar el sistema educativo para que se oriente a la búsqueda del desarrollo de las capacidades antedichas. Supone ello, por supuesto, un excelente trabajo con los maestros para que se oriente en esa dirección toda su labor. Tenemos que transformar la escuela misma, las formas que tenemos actualmente de evaluar. En este punto nosotros hemos venido planteando la necesidad de evaluar de manera diferente en el sistema educativo. No es que la PAES sea instrumento que no sea necesario hacer, pero es insuficiente cuando uno pretende cruzar los resultados de la PAES con el desarrollo de capacidades productivas y ciudadanas. Incluso cuando tenemos un excelente resultado de PAES nosotros no estamos claros que ello suponga un excelente ciudadano y tampoco estamos claros si estos buenos resultados están asociados al buen desarrollo de capacidades productivas.

Entonces debemos ir más allá en esta tarea de reconstrucción del sistema educativo. Estamos haciendo esfuerzos importantes y en esto quiero agradecer públicamente el apoyo que estamos recibiendo de Excelentísima señora Embajadora de la República de Chile, porque estamos muy cerca de que un grupo de expertos chilenos nos apoye en el tema de construcción de ciudadanía. 
Hay que ir más allá de la especialidad. Ahora estamos en el momento de imaginarnos con la disciplina que nosotros dominamos cuál es la capacidad que queremos construir, y es obvio que no se trata de una capacidad que puede construirse desde una sola disciplina y por eso se requiere ir fortaleciendo el trabajo en equipo, es decir, de la planta docente nacional. Se requiere también la búsqueda de las formas más eficientes de construir nuestros futuros maestros. Eso supone una acción que nosotros debemos impulsar en la formación inicial de maestros; supone hacer un trabajo fuerte con la planta de formadores de maestros en todo el sistema de educación superior.

Estamos trabajando en ello y espero que para el 2017 tengamos un trabajo avanzado en esta dirección. Tenemos que ver la formación de maestros en todo sus niveles y por supuesto asegurar que nosotros formamos mejor a nuestros expertos en cada una de las disciplinas. Si conseguimos formar mejor a nuestros formadores de maestros; si nosotros aseguramos mejorar los sistemas de evaluación con esta mirada más exigente de construcción de ciudadano del futuro, creo que podemos hacer cambios importantes en el sistema educativo.

Quiero, además, decir que en este tema de las ciencias sociales, con frecuencia las capacidades ciudadanas son las que se enfatizan y digo capacidades ciudadanas porque cuando uno lee lo que se desarrolla en este tipo de competencias pareciera que las capacidades productivas no están presentes. Por mi parte, soy de los convencidos que las capacidades productivas deben formar parte de las capacidades ciudadanas. Sin embargo, para no confundir las tendencias que hay en la literatura al respecto, creo que mientras no nos convenzamos todos, hay que poner que las capacidades productivas forman parte de la construcción de ciudadanía.

En esto quiero reflexionar sobre algunas cosas que me parece que debemos tomarlas como punto de partida en nuestro sistema educativo. Cuando hablamos de capacidades productivas lo primero que hay que cuestionarse es qué es lo que se pretende producir. Si ustedes se preguntan desde 
la ciencia natural y desde la matemática a nivel de noveno grado, de bachillerato se darán cuenta que no hay respuesta, porque lo que se desarrolla son contenidos y estos desde luego que son necesarios para desarrollar diversos tipos de competencias, pero esas competencias solo se vuelven importantes cuando se desarrollar para enfrentar problemas complejos de la vida.

Mientras no se utilice ese conjunto de competencias para resolver problemas complejos de la vida, esas competencias quedan en el aire, y quedan aún más cuando esas competencias no están asociadas a las vocaciones que tienen las regiones desde el punto de vista productivo y desde el punto de vista de su propia historia. Esto lo hemos venido diciendo en muchas ocasiones en entrevistas: que no es lo mismo ocuparse de un joven que está en bachillerato, por ejemplo, en San Ignacio que uno que está en la Libertad. Si bien es cierto hay una formación en común que debe ser válida para dos regiones diferentes, sino habituamos a nuestros estudiantes a que conozcan la propia riqueza de su región, que conozca su propia historia, las propias vocaciones que tiene la región con respecto a lo qué es la tierra, las tradiciones, etcétera, difícilmente vamos a evitar que esas migraciones típicas en nuestro país sigan sucediendo, no vamos a poder evitarlo.

Cuando la gente migra lo que anda buscando es donde integrarse en el aparato productivo, a fin de cuentas, y como localmente no desarrollamos esa capacidad resulta que siempre van de Morazán o de La Unión para San Miguel, de Ahuachapán o Sonsonate para Santa Ana y de los otros departamentos para San Salvador. Si nosotros no somos capaces de que el sistema educativo se ocupe de investigar las capacidades que tiene cada región y las vocaciones que tienen, creo que seguiremos alentando la migración en nuestro país, y la más grosera, por supuesto, es la que en nuestro propio país no es capaz de retener a la población por el mismo tipo de problema.

En este marco es que este evento se ha organizado. Estamos claros que es un proceso largo y este es el primer evento donde se invita a que reflexionemos sobre estas cosas y que el cambio curricular que vamos a pro- 
vocar sea un cambio que sea de la participación de los más amplios sectores de la sociedad. Por supuesto, que los maestros tienen mucho que aportar en esto, pero no solo este sector, así es que tomen este evento como el inicio de un esfuerzo por transformar nuestro sistema educativo y asegurar que el cambio curricular no va a ser un documento sino que va a ser un cambio que se producirá en el aula.

Muchas gracias. 